Systematic Review

\title{
Mapping hospital antimicrobial stewardship programmes in the Gulf Cooperation Council states against international standards: a systematic review
}

\author{
N. Hashad ${ }^{a}$, D. Perumal ${ }^{b}$, D. Stewart ${ }^{c}$, A.P. Tonna ${ }^{a, *}$ \\ ${ }^{a}$ School of Pharmacy and Life Sciences, Robert Gordon University, Aberdeen, UK \\ ${ }^{\mathrm{b}}$ Commission of Academic Accreditation, Ministry of Education, IPIC Tower, Abu Dhabi, UAE \\ ${ }^{c}$ College of Pharmacy, QU Health, Qatar University, Doha, Qatar
}

\section{A R T I C L E I N F O}

\section{Article history:}

Received 24 June 2020

Accepted 1 September 2020

Available online 8 September

2020

\section{Keywords:}

Antimicrobial

Stewardship

Gulf Cooperation Council

Mapping

Centers for Disease Control and

Prevention

Systematic review

\begin{abstract}
S U M M A R Y
Background: While there is evidence of implementation of antimicrobial stewardship programmes (ASPs) in the Gulf Cooperation Council (GCC) states, there has been limited benchmarking and mapping to international standards and frameworks.

Aim: To critically appraise and synthesize the evidence of ASP implementation in GCC hospitals with reference to the framework of the Centers for Disease Control and Prevention $(C D C)$, identifying key facilitators and barriers.

Methods: A systematic review protocol was developed based on Preferred Reporting Items for Systematic Reviews and Meta-analyses for Protocols guidelines. Five electronic databases were searched for studies published in English from 2010 onwards. Study selection, quality assessment and data extraction were performed independently by two reviewers. A narrative synthesis was conducted with ASP interventions mapped to CDC core elements. Findings: Seventeen studies were identified, most of which $(N=11)$ were from Saudi Arabia. Mapping to the CDC framework identified key areas of strengths and weaknesses in reporting implementation. Studies more commonly reported core elements of pharmacy expertise, selected aspects of implementation actions, tracking, antibiotic use and resistance, and education. Little emphasis was placed on the reporting of leadership and accountability. Key implementation facilitators were physician and organization support, information systems and education, and barriers were dedicated staff, workload and funding.

Conclusion: There is a need to enhance the reporting of ASP implementation in GCC hospitals. The CDC framework should be used as a guide during the development, implementation and reporting of ASP interventions. Action is required to identify facilitators and overcome barriers, where possible.
\end{abstract}

( 2020 The Healthcare Infection Society. Published by Elsevier Ltd. All rights reserved.

\footnotetext{
* Corresponding author. Address: School of Pharmacy and Life Sciences, Robert Gordon University, The Sir lan Wood Building, Garthdee Road, Aberdeen AB10 1JG, UK. Tel.: +44 (0)1224 262578.

E-mail address: a.tonna@rgu.ac.uk (A.P. Tonna).
}

\section{Introduction}

An antimicrobial stewardship programme (ASP) is defined by the World Health Organization (WHO) as 'An organizational or system-wide health-care strategy to promote appropriate use 
of antimicrobials through the implementation of evidencebased interventions [1]. To facilitate successful ASP implementation, several national and international collaborative groups have developed consensus-based interventions [2,3]. These interventions, grouped in toolkits, guidelines or frameworks, have been used in planning, developing, implementing and measuring the impact of ASPs [3] and in guiding audit [4]. Examples of grouped interventions include: 'Start Smart then Focus toolkit' in English hospitals [5], 'European Union Guidelines for the Prudent Use of Antimicrobials in Human Health' [6], and the 'WHO Practical Toolkit for ASP in Healthcare Facilities in Low and Middle Income Countries' [1].

One of the most widely cited grouped interventions is the framework produced by the Centers for Disease Control and Prevention $(C D C)$ which groups interventions for hospitalbased ASPs into seven core elements: hospital leadership; commitment; accountability; pharmacist expertise; actions; tracking; and reporting and education [7]. First published in 2014, the framework was updated in November 2019 to reflect new evidence and experiences gained in the preceding years (see Appendix I, online supplementary material) [8].

In the USA, the CDC Division of Healthcare Quality Promotion uses the framework to evaluate the level of ASP implementation across acute care hospitals, identifying and defining gaps to be addressed at national level $[9,10]$. The framework has also been used in several US studies as an analysis tool to identify gaps in ASP implementation in acute care hospitals [10-13]. In addition, it has been adopted in the development of consensus-based checklists for high- and low-to-middle income countries $[3,4]$.

The Gulf Cooperation Council (GCC) is a political and economic alliance of six countries in the Arabian Peninsula Bahrain, Kuwait, Oman, Qatar, Kingdom of Saudi Arabia (KSA) and United Arab Emirates (UAE). ASP implementation in GCC healthcare systems was largely driven by the increased antimicrobial resistance (AMR) burden and the identification of novel and rare resistance mechanisms [14-16]. Specific reasons for the development of resistance in GCC healthcare systems include: lack of ASP; high burden of broad-spectrum antimicrobial prescribing; outdated hospital architectural design; lack of robust infection control programmes; lack of trained staff; and lack of integrated computerized hospital systems and information technologists $[15,17,18]$. Recognition of the growing burden of AMR led to establishment of the GCC Centre for Infection Control in 2005. A decade later, the Centre published and disseminated the first GCC strategic plan for combating AMR, addressing several aspects (healthcare systems, agriculture and research) with the major strategic aim being to preserve antibiotics from increasing development of resistance [17]. This was a high-level plan which included general recommendations rather than specific actions to implement ASPs, and aimed to complement the global action plan issued by WHO [19]. The task of implementation was then passed on to each individual country. However, there is a paucity of data on the success or otherwise of actual implementation of the plan in each of the countries.

While a number of systematic reviews have summarized components of hospital-based ASPs [20-23], few have focused on specific countries or regions of the Middle East [24] or GCC states [25]. It is well recognized and documented that ASP implementation can vary greatly between geographical regions for different reasons, including diagnostic challenges, variation in knowledge and awareness, access to quality assured antibiotics, structure of healthcare facilities and equipment [26]. Geographically based systematic reviews are therefore important to capture and reflect cultural variations in practice and available resources [3].

Nasr et al. reported a systematic review of antimicrobial utilization and prescribing behaviours in a number of Middle Eastern countries [24]. Two studies reported that the use of proactive core interventions positively affected prescribing behaviours through audit and feedback. The remaining studies primarily described adherence of antimicrobial prescribing to local/national policies or international guidelines.

More recently, Alghamdi et al. reported a systematic review exploring the level of adoption of ASPs in GCC hospitals together with the facilitators, barriers and outcomes of adoption. Outcomes included reduction of: inappropriate antimicrobial prescribing; healthcare-associated infection; direct antimicrobial cost; length of stay; AMR; and broad-spectrum antimicrobial use. ASP adoption was found to be low and under-reported with a lack of a national AMR strategy in the countries included in this systematic review [25].

Neither of these systematic reviews considered ASP implementation with reference to the CDC framework. Mapping ASP implementation to international grouped interventions can assist in the identification of areas of deficiency and in evaluation of the magnitude of success of implementation. Consequently, this will highlight the required actions to improve the quality of service and ensure effective delivery of service by identifying required modifications of actions as well as facilitators and barriers.

This systematic review aimed to critically appraise and synthesize the evidence of ASP implementation in GCC hospitals with reference to the $C D C$ framework, identifying key facilitators and barriers.

\section{Methods}

\section{Protocol development}

The Preferred Reporting Items for Systematic Reviews and Meta-analyses for Protocols (PRISMA-P) standards guided the development of the systematic review protocol, which was registered in the International Prospective Register of Systematic Reviews (PROSPERO) database (CRD42017079597) and is available online $[27,28]$.

\section{Search strategy}

The search was conducted in Medline, Cumulative Index of Nursing and Allied Health Literature, International Pharmaceutical Abstracts, Web of Science and Cochrane databases. Search terms applied to all databases are listed in Appendix II (see online supplementary material). The reference lists of all identified papers were hand-searched to identify any further studies, and database alerts were created for notification of newly published studies during the timeline of the review. A random sample of $10 \%$ of titles, abstracts and full papers was reviewed independently ( $\mathrm{NH}$ and $\mathrm{AT}$ or $\mathrm{DS}$ ) to confirm reliability of the screening process. 


\section{Study inclusion criteria}

Studies were included if they reported ASP implementation within acute care (short-term stay or urgent care) hospital settings in the GCC states. Studies could either report ASPs or any of the specific elements of ASPs, as defined in the core elements of the CDC guidelines [8]. Studies were descriptive with no comparator (other than pre- and postimplementation). Review outcomes were the description of implementation, facilitators and barriers. All primary research studies of any design (quantitative, qualitative or mixed), published in English from 2010 to January 2020, were included. A preliminary search of the peer-reviewed literature did not identify any studies reporting ASP implementation in the GCC prior to 2010, hence this was the search index date. Conference abstracts, proceedings and grey literature were excluded due to the lack of details to permit quality assessment and data extraction in such resources. Studies were excluded if they addressed primary care, nursing homes, outpatient or dental settings.

\section{Quality assessment, data extraction and synthesis}

Specific study quality assessment tools were adopted based on the study design from the National Heart, Lung and Blood Institute [29] and the Consolidated Criteria for Reporting Qualitative Research (COREQ) [30]. Quality assessment tools were applied by two independent reviewers ( $\mathrm{NH}$ plus one of AT, DS or DP), with a third reviewer consulted in the case of disagreement. Quality assessment considered the potential for bias, with studies rated as good, fair or poor [31]. The COREQ checklist was used to evaluate qualitative studies in three domains: research team and reflexivity; study design; and data analysis and reporting [30].

Data extraction was undertaken independently by two reviewers (NH plus one of AT, DS or DP). Data extracted were: aim; setting; study design; dates of data collection; and sample description. Given the lack of homogeneity of the study designs, methods and outcome measures, the results were synthesized using a narrative approach as retrieved data cannot undergo statistical meta-analysis [32]. ASP interventions described were mapped to the seven core elements of the CDC framework [8], which has proven successful as an auditing tool in several US hospitals [10-13]. The core elements were categorized as infrastructure elements (leadership, accountability, pharmacist expertise) and implementation practices (actions, tracking, reporting and education), as described by Pollack et al. [10].

\section{Results}

\section{Study screening}

Eight hundred and ninety-six papers were identified, and the number was reduced to 483 following removal of duplicates. Screening of titles excluded a further 211 papers that were not in the included healthcare setting. Screening of the remaining 272 abstracts excluded a further 218 records that did not meet the objectives of this review. Full paper screening excluded an additional 37 papers ( 28 did not include a description of ASP implementation, four were not conducted in
GCC states, four were abstracts and one was published prior to the search index date). Finally, 17 papers were included in this review: nine cohort studies; six before-after studies; one cross-sectional survey; and one qualitative study. The PRISMA flowchart shown in Figure 1 summarizes the screening and selection process.

\section{Quality assessment}

The quality assessment of studies is summarized in Appendices III and IV (see online supplementary material). Five studies (29.4\%) were rated 'good', 12 (70.6\%) were rated 'fair' and none were rated 'poor'. Key study limitations for the qualitative study were the lack of detail on methodological underpinning, and measures to maximize researcher reflexivity and credibility [33].

The cohort and before-after studies were conducted in KSA $(N=9)$, Qatar $(N=3)$, UAE $(N=2)$ and Kuwait $(N=1)$, with no studies conducted in Bahrain or Oman. Hospitals were described as tertiary $(N=11)$, community $(N=3)$ and quaternary $(N=1)$, with data collected from the entire hospital(s) $(N=9)$, or exclusively from surgical units $(N=3)$, intensive care units $(N=2)$ or specific hospital departments (surgical, obstetrics and gynaecology, medical, critical care, medical intensive care, surgical intensive care unit) $(N=1)$. Data collection periods in the studies ranged from 6 months to 3 years. One study from Saudi Arabia, Mecca, included Hajj time (annual Islamic pilgrimage) in one of the phases of data collection as this mass gathering significantly increases the risk for development of AMR [34].

The cross-sectional study included a total of 184 health professionals practising in six large hospitals in KSA [35]. The qualitative study was also conducted in KSA, comprising 22 interviews with hospital practitioners, managers and Saudi health authority representatives [33]. Hospitals in the crosssectional survey and qualitative study were described as tertiary. Data extraction of the 17 studies is given in Appendix V (see online supplementary material).

\section{Data synthesis}

Data were synthesized according to the aims of the review with ASP interventions mapped to CDC core elements, and facilitators and barriers to implementation.

\section{Mapping of ASP interventions to CDC core elements}

The mapping of the ASP interventions to the CDC core elements is summarized in Table I.

\section{Infrastructure elements}

Only one study reported hospital commitment and leadership support (Core Element 1), described in terms of financial resources, integrated information technology, clinical decision support systems, an identified ASP point of contact and dedicated ASP time for staff [36]. While the involvement of infectious disease (ID) physicians in ASP activities was described in six studies [34,36-40], only two referred to physician leadership with respect to accountability for programme management and outcomes (Core Element 2) [38,40]. Pharmacist expertise (Core Element 3 ) was described in nine studies, five 


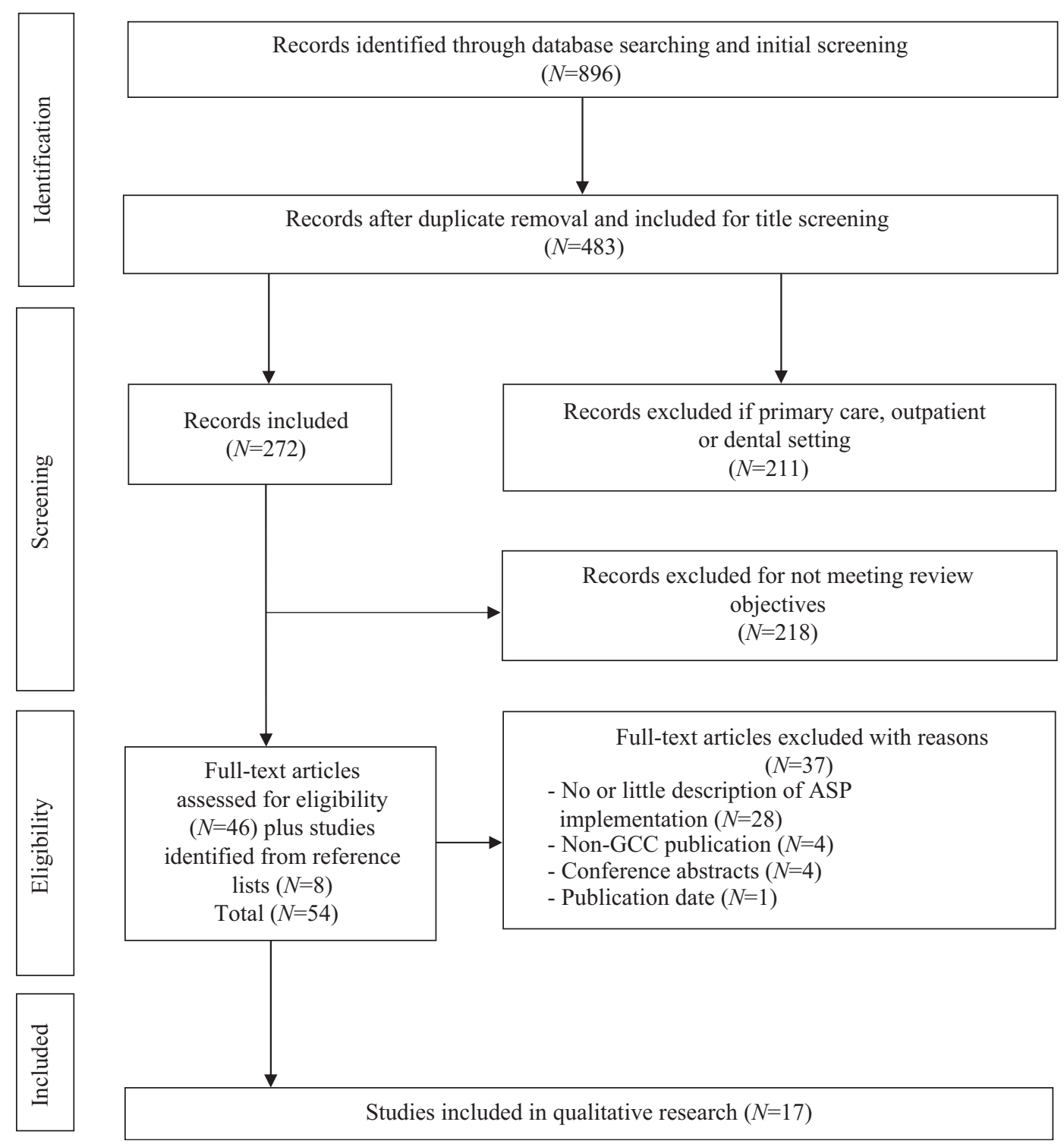

Figure 1. PRISMA flow chart for search and inclusion process. Adapted from Moher et al. [50].

of which reported dedicated full-time ASP pharmacists $[34,36,37,41,42]$ and one had a pharmacist with special ID training [36]. The other studies only reported pharmacist involvement in monitoring antimicrobial consumption [39,43-45].

\section{Implementation practices}

All studies described practices related to Core Element 4 (actions), although the specific descriptions of the scope of practices varied. The majority of the studies reported locally developed guidelines based on antimicrobial culture and sensitivity testing, as recommended in the CDC framework $[33,35-38,41,44,46-49]$. Prospective audit and feedback were the most commonly reported practices [34,36-40,42-44,48], followed by pre-authorization [33, 35, 36, 39, 40,42,43].

Pharmacy-based interventions largely comprised documentation of indication for antibiotic use in patients' medical records, as described in 10 studies $[34,36,37,39,40,43,44,47-49]$. Only six studies reported optimizing antimicrobial dose [36-40,45], three of which also emphasized dose adjustment $[37,39,40]$. The remaining pharmacy-based interventions - namely time-sensitive automatic stop order, intravenous to oral switch, and duplicative therapy alerts - were minimally reported, and detection and prevention of antibiotic-related drug-drug interactions were not reported at all.

Provider-based interventions were seldom reported, with antibiotic 'timeouts' described in three studies [36,45,48]. None of the papers refer to assessing patients for penicillin allergy.

Microbiology-based interventions and infection-based interventions were scarcely reported, with only one study describing the effect of selective reporting of antimicrobial susceptibilities [41], and another study referred to comments in microbiology reports [42]. Notably, none of the studies reported any nursing-based interventions.

Core Element 5 (tracking) is classified as antibiotic use measures, and outcome measures and process measures for quality improvement. The majority of studies reported at least 


\begin{tabular}{|c|c|c|c|c|c|c|c|c|c|c|c|c|c|c|c|c|c|c|}
\hline & $\begin{array}{l}\text { Dib } \\
\text { et } \\
\text { al., } \\
2009\end{array}$ & $\begin{array}{l}\text { Aly } \\
\text { et } \\
\text { al., } \\
2012\end{array}$ & $\begin{array}{l}\text { Al- } \\
\text { Tawfiq, } \\
2013\end{array}$ & $\begin{array}{l}\text { Amer } \\
\text { et } \\
\text { al., } \\
2013\end{array}$ & $\begin{array}{l}\text { Al- } \\
\text { Somai } \\
\text { et al., } \\
2014\end{array}$ & $\begin{array}{l}\text { Al- } \\
\text { Tawfiq } \\
\text { et al., } \\
2015\end{array}$ & $\begin{array}{l}\text { El } \\
\text { Hassan } \\
\text { et al., } \\
2015\end{array}$ & $\begin{array}{l}\text { Tobaiqy } \\
\text { et al., } \\
2015\end{array}$ & $\begin{array}{l}\text { Alawi and } \\
\text { Darwesh, } \\
2016\end{array}$ & $\begin{array}{l}\text { Garcell } \\
\text { et al., } \\
2016\end{array}$ & $\begin{array}{l}\text { Abdallah } \\
\text { et al., } \\
2017\end{array}$ & $\begin{array}{c}\text { Garcell } \\
\text { et al., } \\
2017\end{array}$ & $\begin{array}{l}\text { Garcell } \\
\text { et al., } \\
2017\end{array}$ & $\begin{array}{l}\text { Momattin } \\
\text { et al., } \\
2018\end{array}$ & $\begin{array}{l}\text { Baraka } \\
\text { et al., } \\
2019\end{array}$ & $\begin{array}{l}\text { Alghamdi } \\
\text { et al., } \\
2019\end{array}$ & $\begin{array}{l}\text { El- } \\
\text { Lababidi } \\
\text { et al., } \\
2019\end{array}$ & Total \\
\hline & [37] & {$[46]$} & [38] & [39] & [34] & [41] & [47] & [40] & [43] & [48] & [42] & [49] & [44] & [45] & [35] & [33] & [36] & \\
\hline \multicolumn{19}{|c|}{ Infrastructure elements (leadership, accountability and pharmacy expertise) } \\
\hline $\begin{array}{l}\text { Core Element 1: Hospital } \\
\text { leadership } \\
\text { commitment }\end{array}$ & & & & & & & & & & & & & & & & & $\sqrt{ }$ & 1 \\
\hline $\begin{array}{l}\text { Core Element 2: } \\
\text { Accountability for } \\
\text { programme } \\
\text { management and } \\
\text { outcome }\end{array}$ & & & $\sqrt{ }$ & & & & & $\sqrt{ }$ & & & & & & & & & & 2 \\
\hline $\begin{array}{l}\text { Core Element 3: } \\
\text { Pharmacy expertise }\end{array}$ & $\sqrt{ }$ & & & $\sqrt{ }$ & $\sqrt{ }$ & $\sqrt{ }$ & & & $\sqrt{ }$ & & $\sqrt{ }$ & & $\sqrt{ }$ & $\sqrt{ }$ & & & $\sqrt{ }$ & 9 \\
\hline \multicolumn{19}{|c|}{ Implementation practices (actions, tracking, reporting and education) } \\
\hline \multicolumn{19}{|c|}{$\begin{array}{l}\text { Core Element 4: Actions that implement interventions that report antibiotic use } \\
\text { A. High-priority interventions }\end{array}$} \\
\hline $\begin{array}{l}\text { Prospective audit and } \\
\text { feedback }\end{array}$ & $\sqrt{ }$ & & $\sqrt{ }$ & $\sqrt{ }$ & $\sqrt{ }$ & & & $\sqrt{ }$ & $\sqrt{ }$ & $\sqrt{ }$ & $\sqrt{ }$ & & $\sqrt{ }$ & & & & $\sqrt{ }$ & 10 \\
\hline Pre-authorization & & & & $\sqrt{ }$ & & & & $\sqrt{ }$ & $\sqrt{ }$ & & $\sqrt{ }$ & & & & $\sqrt{ }$ & $\sqrt{ }$ & $\sqrt{ }$ & 7 \\
\hline $\begin{array}{l}\text { Facility-specific } \\
\text { treatment guidelines }\end{array}$ & $\sqrt{ }$ & $\sqrt{ }$ & $\sqrt{ }$ & & & $\sqrt{ }$ & $\sqrt{ }$ & & & $\sqrt{ }$ & & $\sqrt{ }$ & $\sqrt{ }$ & & $\sqrt{ }$ & $\sqrt{ }$ & $\sqrt{ }$ & 11 \\
\hline \multicolumn{19}{|c|}{ B. Actions focusing on the most common indications for hospital antibiotic use (common infection-based interventions) } \\
\hline Urinary tract infections & & & & & & & & & & & & & & & & & & 0 \\
\hline $\begin{array}{l}\text { Community-acquired } \\
\text { pneumonia }\end{array}$ & & & & & & & & & & $\sqrt{ }$ & & & & $\sqrt{ }$ & & & & 2 \\
\hline $\begin{array}{l}\text { Skin and soft tissue } \\
\text { infection }\end{array}$ & & & & & & & & & & & & & & & & & & 0 \\
\hline \multicolumn{19}{|c|}{ C. Actions focusing on less common indications for hospital antibiotic use (less common infection-based interventions) } \\
\hline Sepsis & & & & & & & & & & & & & & & & & & 0 \\
\hline $\begin{array}{l}\text { Meticillin-resistant } \\
\text { Staphylococcus aureus }\end{array}$ & $\sqrt{ }$ & & & & & & & & & & & & & & & & $\sqrt{ }$ & 2 \\
\hline Clostridioides difficile & & & & $\sqrt{ }$ & & $\sqrt{ }$ & & & & & & & & & & & $\sqrt{ }$ & 3 \\
\hline $\begin{array}{l}\text { Culture-proven invasive } \\
\text { infection }\end{array}$ & & & & & & & & & & & & & & & & & & 0 \\
\hline $\begin{array}{l}\text { Review of planned } \\
\text { outpatient parenteral } \\
\text { antibiotic therapy }\end{array}$ & & & & & & & & & & & & & & & & & & 0 \\
\hline \multicolumn{19}{|c|}{ D. Provider-based intervention } \\
\hline Antibiotic 'timeout' & & & & & & & & & & $\sqrt{ }$ & & & & $\sqrt{ }$ & & & $\sqrt{ }$ & 3 \\
\hline
\end{tabular}


allergy

E. Pharmacy-based interventions

Documentation of

$\sqrt{ } \quad \sqrt{ }$

indication

Automatic IV to oral

switch

Dose adjustment

Dose optimization

Duplicative therapy

alerts

Time-sensitive

automatic stop order

Detection and

prevention of

antibiotic-related drug

-drug interaction

F. Microbiology-based interventions

Selective reporting of

antimicrobial

susceptibility testing

results

Comments in

microbiology reports

G. Nursing-based interventions

Optimizing antimicrobial

cultures

IV to oral transitions

Promote antibiotic

review 'timeout'

Core Element 5: Tracking

A. Antibiotic use measures

Consumption data

reported as days of

therapy or defined

daily doses

B. Outcome measures

Clostridioides difficile

infection

Antibiotic resistance

patterns

Financial impact in terms

of cost reduction

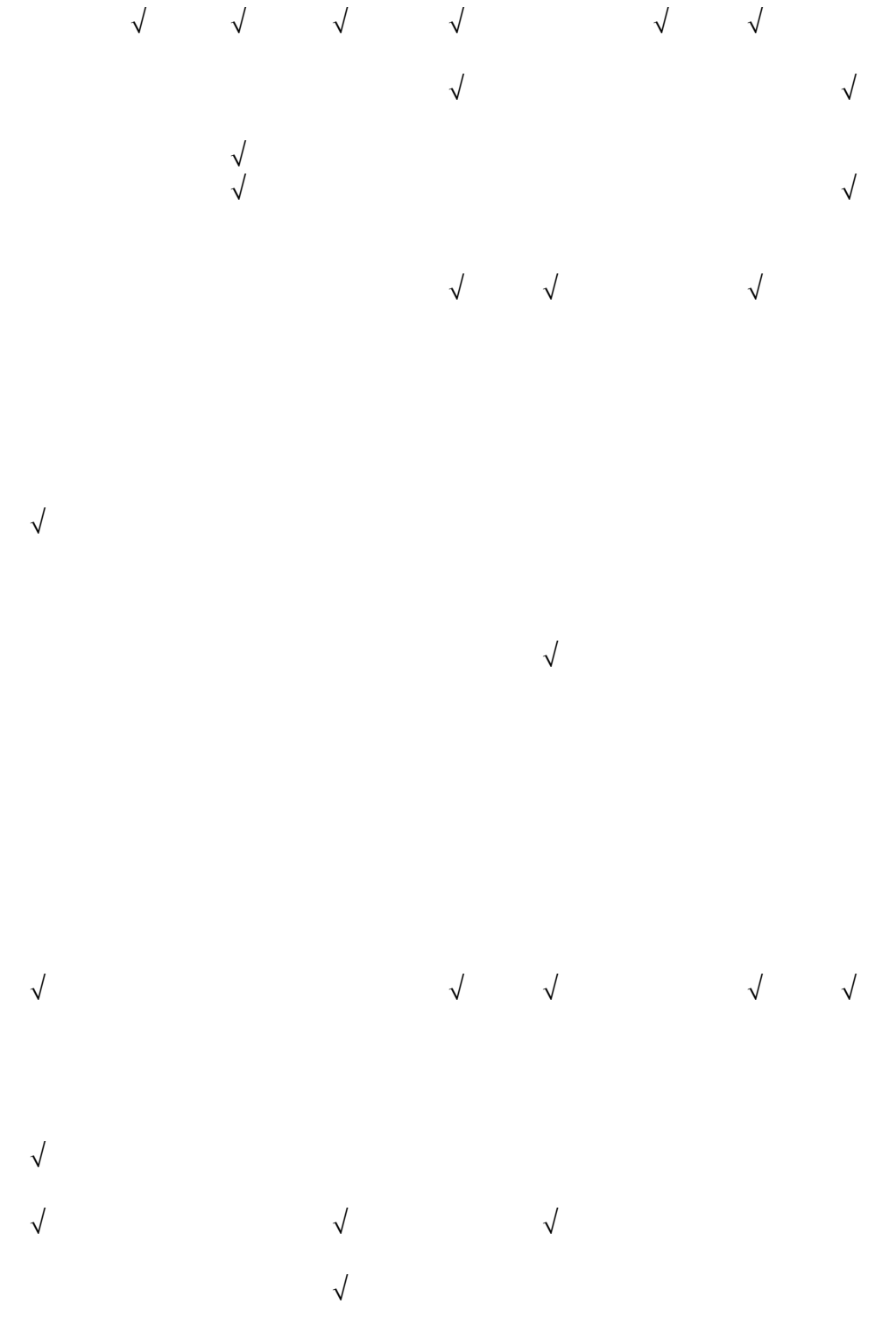




\begin{tabular}{|c|c|c|c|c|c|c|c|c|c|c|c|c|c|c|c|c|c|c|}
\hline & $\begin{array}{c}\text { Dib } \\
\text { et } \\
\text { al., } \\
2009\end{array}$ & $\begin{array}{c}\text { Aly } \\
\text { et } \\
\text { al., } \\
2012\end{array}$ & $\begin{array}{c}\text { Al- } \\
\text { Tawfiq, } \\
2013\end{array}$ & $\begin{array}{c}\text { Amer } \\
\text { et } \\
\text { al., } \\
2013\end{array}$ & $\begin{array}{l}\text { Al- } \\
\text { Somai } \\
\text { et al., } \\
2014\end{array}$ & $\begin{array}{c}\text { Al- } \\
\text { Tawfiq } \\
\text { et al., } \\
2015\end{array}$ & $\begin{array}{c}\text { El } \\
\text { Hassan } \\
\text { et al., } \\
2015\end{array}$ & $\begin{array}{c}\text { Tobaiqy } \\
\text { et al., } \\
2015\end{array}$ & $\begin{array}{l}\text { Alawi and } \\
\text { Darwesh, } \\
2016\end{array}$ & $\begin{array}{l}\text { Garcell } \\
\text { et al., } \\
2016\end{array}$ & $\begin{array}{l}\text { Abdallah } \\
\text { et al., } \\
2017\end{array}$ & $\begin{array}{l}\text { Garcell } \\
\text { et al., } \\
2017\end{array}$ & $\begin{array}{l}\text { Garcell } \\
\text { et al., } \\
2017\end{array}$ & $\begin{array}{l}\text { Momattin } \\
\text { et al., } \\
2018\end{array}$ & $\begin{array}{l}\text { Baraka } \\
\text { et al., } \\
2019\end{array}$ & $\begin{array}{l}\text { Alghamdi } \\
\text { et al., } \\
2019\end{array}$ & $\begin{array}{c}\text { El- } \\
\text { Lababidi } \\
\text { et al., } \\
2019\end{array}$ & Total \\
\hline & [37] & [46] & [38] & [39] & [34] & [41] & [47] & [40] & [43] & [48] & [42] & [49] & [44] & [45] & [35] & [33] & [36] & \\
\hline \multicolumn{19}{|c|}{$\begin{array}{l}\text { C. Process measures for quality improvement focusing on specific interventions implemented in the hospital } \\
\text { Priority process measures }\end{array}$} \\
\hline $\begin{array}{l}\text { Tracking prospective } \\
\text { audit and feedback }\end{array}$ & & & & & & & & & & & & & & & & & & 0 \\
\hline $\begin{array}{l}\text { Monitoring pre- } \\
\text { authorization }\end{array}$ & & & & & & & & & & & & & & & & & & 0 \\
\hline $\begin{array}{l}\text { Monitoring adherence to } \\
\text { facility-specific } \\
\text { treatment guidelines }\end{array}$ & & $\sqrt{ }$ & & & & & $\checkmark$ & & & $\checkmark$ & & $\checkmark$ & $\checkmark$ & & & & $\checkmark$ & 7 \\
\hline \multicolumn{19}{|c|}{ Additional process measures } \\
\hline $\begin{array}{l}\text { Monitor antibiotic } \\
\text { 'timeouts' }\end{array}$ & & & & & & & & & & & & & & & & & $\checkmark$ & 1 \\
\hline $\begin{array}{l}\text { Performing medication } \\
\text { use evaluation }\end{array}$ & & & & & $\sqrt{ }$ & & & & & & & & & & & & & 1 \\
\hline Monitor IV to oral switch, & & & & & & & & & & & & & & & & & $\sqrt{ }$ & 1 \\
\hline $\begin{array}{l}\text { Monitor unnecessary } \\
\text { duplicates in therapy }\end{array}$ & & & & & & & & & & & & & & & & & & 0 \\
\hline $\begin{array}{l}\text { Monitor discharge on } \\
\text { correct antibiotic }\end{array}$ & & & & & & & & & & & & & & & & & & 0 \\
\hline $\begin{array}{l}\text { Core Element } 6 \text { : } \\
\text { Reporting on antibiotic } \\
\text { use and resistance }\end{array}$ & $\sqrt{ }$ & & & $\sqrt{ }$ & $\sqrt{ }$ & $\sqrt{ }$ & & & $\sqrt{ }$ & $\sqrt{ }$ & & $\sqrt{ }$ & $\sqrt{ }$ & & & & $\sqrt{ }$ & 9 \\
\hline $\begin{array}{l}\text { Core Element 7: } \\
\text { Education }\end{array}$ & $\checkmark$ & & & $\sqrt{ }$ & & $\sqrt{ }$ & & & & $\sqrt{ }$ & & $\sqrt{ }$ & $\sqrt{ }$ & $\sqrt{ }$ & & & $\checkmark$ & 8 \\
\hline \multicolumn{19}{|l|}{ IV, intravenous. } \\
\hline
\end{tabular}


one of the CDC tracking measures. Eight studies monitored antibiotic use by reporting defined daily doses (DDDs) $[34,39,41,42,44,45,48]$ or days of therapy (DoT) [36,45]. Alawi et al. monitored the number of units of restricted antibiotics pre- and post-implementation [43]. All of these studies showed a significant decline in antimicrobial consumption with optimizing antibiotic use.

The specific outcome measures described in Core Element 5 (financial impact, antimicrobial resistance or Clostridioides difficile infection) were all minimally reported. Studies addressing financial impact have shown variable reduction in antimicrobial expenditure from pre-intervention or initial phase of intervention $[36,39,43]$. Four studies reported a significant decline in infection rate by multi-drug-resistant organisms [36,41-43], and three studies described a significant reduction in the $C$. difficile-associated disease rate $[36,39,41]$.

Among the different process measures for quality improvement (high priority and additional measures), monitoring adherence to local facility-specific guidelines was the most commonly reported measure, described in seven studies. Increased adherence and compliance with local hospital guidelines was observed over the duration of the study in five studies [36,37,44,48,49], while the remaining two studies reported low compliance rates $[46,47]$. Other additional process measures as specified in the CDC framework, on monitoring antibiotic timeout and intravenous to oral switch [36] as well as the evaluation of medication use [34], were minimally reported.

Reported outcomes (not part of the CDC framework) were: faster rate of transfer from intensive care unit to regular ward with 4-5 days of follow-up [39]; and ID consultation with beneficial impact on antimicrobial utilization [36,38].

Core Element 6 (personal communication with staff to improve antibiotic use and resistance) was reported in nine studies [34,36,37,39,41,43,44,48,49], four of which described circulating facility-specific reports on antibiotic use to prescribers $[39,44,48,49]$. In two studies, an antibiogram was distributed to prescribers $[36,41]$.

Eight studies described Core Element 7 (education of prescribers and healthcare workers), comprising small group meetings, verbal and personal communications, and e-mail reminders $[36,37,39,41,44,45,48,49]$.

\section{Facilitators and barriers to implementation}

While facilitators and barriers to implementation were reported in the majority of studies $(N=14)$, the scope and detail of description varied widely. These were described in terms of regional and national levels, hospital organizational level, and hospital culture and environment. Education and training were the most commonly reported facilitators, followed by the involvement of pharmacist, microbiology and infection control personnel. There appeared to be less focus on investigating barriers; when reported, a lack of higher managerial support was most common (see Tables II and III).

While one study from Saudi Arabia reported that regional and national legislation facilitated implementation in Saudi Arabia, the lack of enforcement of the legislation and lack of surveillance were reported as barriers [33].

In terms of hospital organizational facilitators, five studies reported higher managerial support $[33,35,36,39,49]$ through addressing several issues such as: policy enforcement [33]; lack of ASP-dedicated staff, including the lack of ID physicians and clinical pharmacists; workload associated with ASP audits; lack of novel diagnostics and insufficient funding [39]; and mandating infection prevention and medication safety educational activities [49].

For human resources, the importance of the contribution of ASP personnel was highlighted in 10 studies [34-39,41,46,47,49]. Lack of personnel dedicated to ASP activities was reported as a major barrier to effective ASP implementation [33,35,39,43], notably increased workload associated with audits $[35,39,43]$ and high turnover of physicians [43].

For information resources, education and training of healthcare professionals was the most commonly reported facilitator through various forms of education, hospital policies and guidelines [33,35, 37,39,41,43,46,47,49]. Lack of education and training on local hospital guidelines was considered a major barrier [33,35,37,46,49], especially in newly established settings with staff with diverse backgrounds and a range of experiences [49]. Information technology support has been reported as a solution to support the implementation of hospital policies and guidelines [33,35,36,39,46].

For hospital functionality, several studies addressed the diagnostic and prescribing challenges faced by physicians leading to potential unnecessary antibiotic prescribing $[33,41,43,46]$. Diagnostic challenges took the form of inaccurate diagnosis, imprecise recognition of conditions warranting antibiotics, inconsistent availability of antibiotics [43], lack of microbiological testing and suboptimal triage systems [41]. Novel diagnostic systems such as procalcitonin biomarker [46] and enhancing the availability of antimicrobial susceptibility testing were potential solutions to diagnostic and prescribing barriers [35,36, 39, 41,42].

The effect of hospital culture and environment was addressed in several studies. Factors such as resistance to changing prescribing habits $[43,46]$, fear of liability risk [46], lack of confidence [35] and poor communication among teams [33] were identified. Lack of adherence to guidelines was suggested to be due to lack of awareness of the existence of such policies $[33,35]$.

\section{Discussion}

\section{Statement of key findings}

The reporting of ASP implementation aligned to the CDC framework was variable and generally incomplete. The most commonly reported core elements were: pharmacy expertise; aspects of implementation actions; reporting on antibiotic use and resistance; and education. Seldom reported core elements were: hospital leadership commitment; accountability for programme management and outcome; and tracking. Key implementation facilitators were physician and organization support, information systems and education, and barriers were dedicated staff, workload and funding.

\section{Strengths and limitations}

There are several strengths to this review. The protocol was developed according to the PRISMA-P standards [27], 
Table II

Facilitators to antimicrobial stewardship programme (ASP) implementation reported in included studies $(N=17)$

\begin{tabular}{|c|c|c|c|c|c|c|c|c|c|c|c|c|c|c|c|c|c|}
\hline $\begin{array}{l}\text { Dib } \\
\text { t al., } \\
2009 \\
{[37]}\end{array}$ & $\begin{array}{c}\text { Aly } \\
\text { et al., } \\
2012 \\
{[46]}\end{array}$ & $\begin{array}{c}\text { Al- } \\
\text { Tawfiq, } \\
2013 \\
{[38]}\end{array}$ & $\begin{array}{c}\text { Amer } \\
\text { et al., } \\
2013 \\
{[39]}\end{array}$ & $\begin{array}{c}\text { Al- } \\
\text { Somai } \\
\text { et al., } \\
2014 \\
{[34]}\end{array}$ & $\begin{array}{c}\text { Al- } \\
\text { Tawfiq } \\
\text { et al., } \\
2015 \\
\text { [41] }\end{array}$ & $\begin{array}{c}\text { El } \\
\text { Hassan } \\
\text { et al., } \\
2015 \\
{[47]}\end{array}$ & $\begin{array}{c}\text { Tobaiqy } \\
\text { et al., } \\
2015 \\
\text { [40] }\end{array}$ & $\begin{array}{l}\text { Alawi and } \\
\text { Darwesh, } \\
2016 \text { [43] }\end{array}$ & $\begin{array}{c}\text { Garcell } \\
\text { et al., } \\
2016 \\
{[48]}\end{array}$ & $\begin{array}{l}\text { Abdallah } \\
\text { et al., } \\
2017 \text { [42] }\end{array}$ & $\begin{array}{c}\text { Garcell } \\
\text { et al., } \\
2017 \\
{[49]}\end{array}$ & $\begin{array}{c}\text { Garcell } \\
\text { et al., } \\
2017 \\
{[44]}\end{array}$ & $\begin{array}{l}\text { Momattin } \\
\text { et al., } \\
2018 \text { [45] }\end{array}$ & $\begin{array}{c}\text { Baraka } \\
\text { et al., } \\
2019 \\
{[35]}\end{array}$ & $\begin{array}{l}\text { Alghamdi } \\
\text { et al., } \\
2019 \text { [33] }\end{array}$ & $\begin{array}{c}\text { El- } \\
\text { Lababidi } \\
\text { et al., } \\
2019 \text { [36] }\end{array}$ & Total \\
\hline
\end{tabular}

\begin{tabular}{|c|c|c|c|c|c|c|c|c|}
\hline \multicolumn{9}{|c|}{$\begin{array}{l}\text { Facilitators } \\
\text { A. Regional and national }\end{array}$} \\
\hline \multicolumn{9}{|c|}{$\begin{array}{l}\text { Regional and national } \\
\text { legislation }\end{array}$} \\
\hline \multicolumn{9}{|c|}{$\begin{array}{l}\text { B. Hospital organizational } \\
\text { level }\end{array}$} \\
\hline \multicolumn{9}{|c|}{ Higher managerial support } \\
\hline \multirow[t]{2}{*}{$\begin{array}{l}\text { Human } \\
\text { resources }\end{array}$} & $\begin{array}{l}\text { Pharmacist } \\
\text { feedback }\end{array}$ & $\sqrt{ }$ & & & $\sqrt{ }$ & $\sqrt{ }$ & $\sqrt{ }$ & $\sqrt{ }$ \\
\hline & $\begin{array}{l}\text { Microbiology } \\
\text { and infection } \\
\text { control } \\
\text { personnel } \\
\text { involvement }\end{array}$ & $\sqrt{ }$ & $\sqrt{ }$ & $\sqrt{ }$ & $\sqrt{ }$ & & $\sqrt{ }$ & \\
\hline \multirow[t]{5}{*}{$\begin{array}{r}\text { Information } \\
\text { resources }\end{array}$} & $\begin{array}{l}\text { Formulary } \\
\text { management }\end{array}$ & & & & & & & \\
\hline & $\begin{array}{l}\text { Institutional } \\
\text { policy and } \\
\text { guidelines } \\
\text { Supplemental } \\
\text { online ASP } \\
\text { resources }\end{array}$ & & $\sqrt{ }$ & & & & & $\sqrt{ }$ \\
\hline & $\begin{array}{l}\text { Education and } \\
\text { training for } \\
\text { healthcare } \\
\text { professionals }\end{array}$ & $\sqrt{ }$ & $\sqrt{ }$ & & $\sqrt{ }$ & & $\sqrt{ }$ & $\sqrt{ }$ \\
\hline & $\begin{array}{l}\text { Education and } \\
\text { training for } \\
\text { undergraduate } \\
\text { medical } \\
\text { students and at } \\
\text { an early stage } \\
\text { of medical } \\
\text { training }\end{array}$ & & & & & & $\sqrt{ }$ & \\
\hline & $\begin{array}{l}\text { Integrating } \\
\text { clinical } \\
\text { decision } \\
\text { support system } \\
\text { in hospital IT } \\
\text { system }\end{array}$ & & $\sqrt{ }$ & & $\sqrt{ }$ & & & \\
\hline
\end{tabular}

resources

training for

system 


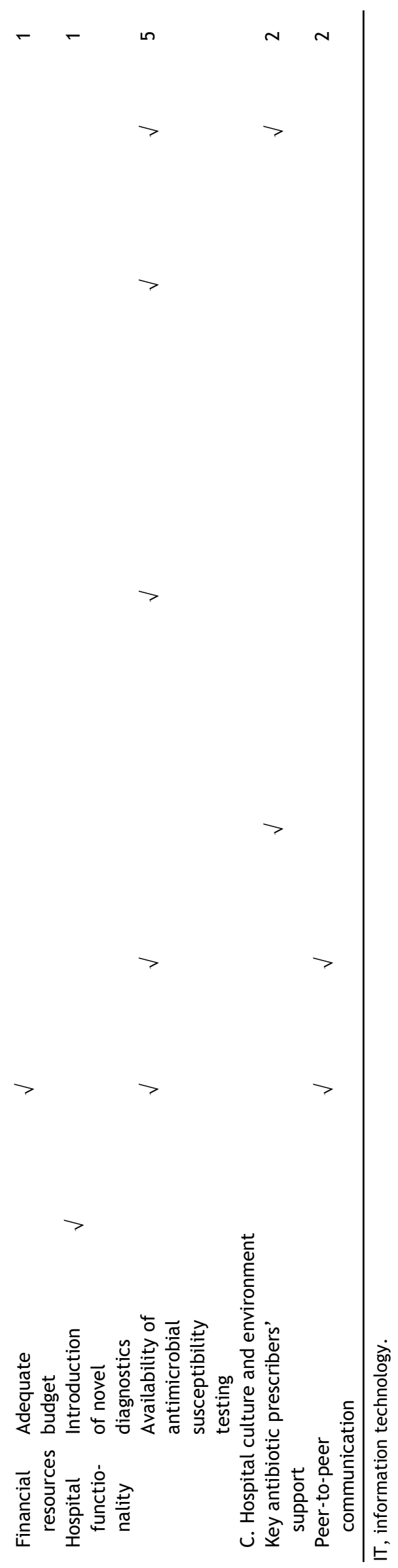

registered in the PROSPERO database [28], and the systematic review was reported according to PRISMA criteria [50]. One key strength is the approach to synthesis of information on ASP implementation using the CDC framework, which will facilitate international comparison. However, there are some weaknesses, so the review findings should be interpreted with caution. Restricting the search to studies published in English, and excluding those written in Arabic, may have limited the retrieval of potentially relevant studies. However, English is the preferred language of most professional organizations in the GCC states. While there was rationale in restricting the review to studies conducted in the GCC states, this may have reduced the potential generalizability and transferability to other countries in the Middle East and beyond. Of note, the majority of the studies included were from KSA.

\section{Interpretation of key findings}

Mapping studies to standardized quality criteria identified that most were of fair quality, often with small sample sizes, hence emphasizing the need for higher quality, larger, more robust studies with greater consideration of validity and reliability.

Implementation research in the healthcare sector focuses on a full and complete description of the implementation processes, allowing for consideration of contextual factors that affect delivery of the intervention and provide a link between what can be theoretically achieved and real-life practice [51]. For successful implementation, researchers are encouraged to focus on factors such as process of implementation, context, influencing factors and evaluation [52] which facilitate improvement, accountability and long-term sustainability [53]. Furthermore, complete description of the intervention, together with details about real-world setting conditions, will enable understanding of what was actually implemented, thus aiding replication $[53,54]$.

Implementation frameworks ideally provide focus on the nature of the interventions and the implementation processes, thus facilitating interpretation of implementation outcomes [51]. Given that these frameworks target specific components, they must be selected with care [52]. This systematic review used the CDC framework to provide a complete description of ASP interventions and implementation, with elements relevant to infrastructure, practices and monitoring [8]. Furthermore, the $C D C$ framework has been adopted by Joint Commission International, the most widely sought accreditation body across GCC hospitals [55,56], as an ASP standard for hospital accreditation [8,57], which is an added strength and further adds to the relevance of the results in the GCC context. While most studies in this review had key limitations when mapped to this framework, it should be borne in mind that these may reflect deficiencies in study reporting, and not necessarily weaknesses in ASP interventions and implementation. Compliance with the framework was found to be variable outwith GCC studies [58,59], reaching almost $100 \%$ in US studies [10-13] where the CDC framework is adopted at a US national level. Of note, the compliance of GCC studies with the CDC core elements has increased in recent years, especially with the release of the AMR strategic plan for the GCC Centre for Infection Control [17] and inclusion of ASPs in the Joint Commission International accreditation standards [57], which 


\begin{tabular}{|c|c|c|c|c|c|c|c|c|c|c|c|c|c|c|c|c|c|}
\hline $\begin{array}{c}\text { Dib et al., } 2009 \\
\text { [37] }\end{array}$ & $\begin{array}{c}\text { Aly } \\
\text { et al., } \\
2012 \\
{[46]}\end{array}$ & $\begin{array}{c}\text { Al- } \\
\text { Tawfiq, } \\
2013 \\
{[38]}\end{array}$ & $\begin{array}{c}\text { Amer } \\
\text { et al., } \\
2013 \\
{[39]}\end{array}$ & $\begin{array}{c}\text { Al- } \\
\text { Somai } \\
\text { et al., } \\
2014 \\
{[34]}\end{array}$ & $\begin{array}{c}\text { Al- } \\
\text { Tawfiq } \\
\text { et al., } \\
2015 \\
{[41]}\end{array}$ & $\begin{array}{c}\text { El } \\
\text { Hassan } \\
\text { et al., } \\
2015 \\
{[47]}\end{array}$ & $\begin{array}{c}\text { Tobaiqy } \\
\text { et al., } \\
2015 \\
\text { [40] }\end{array}$ & $\begin{array}{l}\text { Alawi and } \\
\text { Darwesh, } \\
2016 \text { [43] }\end{array}$ & $\begin{array}{c}\text { Garcell } \\
\text { et al., } \\
2016 \\
{[48]}\end{array}$ & $\begin{array}{l}\text { Abdallah } \\
\text { et al., } \\
2017 \text { [42] }\end{array}$ & $\begin{array}{c}\text { Garcell } \\
\text { et al., } \\
2017 \\
{[49]}\end{array}$ & $\begin{array}{c}\text { Garcell } \\
\text { et al., } \\
2017 \\
{[44]}\end{array}$ & $\begin{array}{l}\text { Momattin } \\
\text { et al., } \\
2018 \text { [45] }\end{array}$ & $\begin{array}{c}\text { Baraka } \\
\text { et al., } \\
2019 \\
{[35]}\end{array}$ & $\begin{array}{l}\text { Alghamdi } \\
\text { et al., } \\
2019 \text { [33] }\end{array}$ & $\begin{array}{c}\text { El- } \\
\text { Lababidi } \\
\text { et al., } \\
2019[36]\end{array}$ & Total \\
\hline
\end{tabular}

\section{Barriers}

A. Regional and national level

Lack of

enforcement of

national

legislations

Lack of AMR and

antibiotic

consumption

national

surveillance

systems

B. Hospital organizational level

Lack of higher

managerial

support

Human resources Lack of

dedicated ASP

personnel

Shortage of ID

physicians

Shortage of

microbiologist

Lack of

clinical

pharmacist

Physicians'

high turnover

Physicians'

high workload

and limited

time

Lack of

v

internal policy

and guidelines

Lack of

education and

training on

local hospital

guidelines 
Lack of ASP

Financial Limited

resources funding

Hospital Microbiology-

Microbiology- $\quad \sqrt{ }$

functionality related

barriers

Diagnostic

challenges

C. Hospital culture and environment

Lack of

confidence

Poor

communication

among teams

Fear of liability

risk

Lack of support

from senior to

junior staff

Physicians'

resistance to

changing their

prescribing

habits

Lack of

adherence to

guidelines

AMR, antimicrobial resistance; ID, infectious diseases; IT, information technology. 
reflects the increased importance of ASPs in confronting the increasing risk of AMR.

A collaborative approach engaging all key stakeholder groups in intervention development and implementation is more likely to result in successful outcomes generally [51], as well as those specifically related to ASP implementation $[1,8,10,60]$. One limitation of the studies in this systematic review was the lack of input from regulatory authorities, which was cited as a barrier to ASP implementation. Indeed, there were reports of only two GCC states having a national action plan to combat AMR $[61,62]$, as promoted by WHO, to provide a framework of actions required in the battle against AMR [19]. This limitation was also reported as a finding of two other systematic reviews conducted in the Middle East [24,25]. Further evidence of a less well established ASP infrastructure as defined by CDC [8] is noted, with hospital leadership support (Core Element 1) only described in one study [36], and accountability for programme management (Core Element 2) described in another two studies [38,40]. It is evident that positive collaboration between key stakeholders at different levels can identify barriers to implementation and promote an iterative approach to improvement [51].

According to the WHO ASP toolkit [1], the ASP team should be multi-disciplinary comprising physicians, pharmacists, nurses and microbiologists [1,5,6,8], including ID physicians, ID-trained pharmacists and infection prevention and control specialists where available [1]. This systematic review identified potential barriers to ASP implementation with reported shortages of ID physicians and limited contributions from pharmacists, infection control preventionists, microbiologists and nurses $[33,35,39,43]$. Given the global shortage of healthcare professionals [63] and the difficulties of establishing an ASP team [64-66], consideration should be given to optimizing the contribution of existing professionals through role extension [67] and professional development [36,68].

Smart clinical decision support systems can leverage ASP implementation, especially when linked to antimicrobial resistance surveillance tools and antibiotic prescribing guidelines [69]. This was identified as a facilitator in the studies included in this review $[33,35,36,39,46]$, and similar observations were reported in other non-GCC studies $[69,70]$. Embedding such smart clinical decision support systems linked to validated antimicrobial prescribing guidelines, to ensure appropriateness to the local context, could enhance the effectiveness and efficiency of ASP implementation with consequences for resources and outcomes [71]. Furthermore, facilitating education (Core Element 7) as well as training is crucial in terms of changing practice habits, especially in a diversity of backgrounds as present in GCC hospitals. It is recommended that GCC hospitals should include ASP education in hospital seminars, ward rounds and annual meetings [72].

Central to the continuum of implementation research is ongoing evaluation, allowing pre-implementation insights into intervention suitability, monitoring change in practice during implementation, and observing post-implementation impact and consequences [51,52,73]. CDC categorized tracking (Core Element 5) into antimicrobial consumption, outcome measures and process measures [8]. However, according to this systematic review, the current focus in GCC states is on evaluation of the implementation phase, with the majority of included studies reporting antimicrobial consumption $[34,36,39,41,42,44,45,48]$ and adherence to facility-specific treatment guidelines [36,37,44,46-49] as the indicators of successful ASP implementation, and only a few studies reporting other tracking measures. There is a need to focus on exploring and maintaining positive outcomes in the long term after overcoming implementation challenges [74]. As ASP implementation continues to evolve and mature in GCC states, more focus should be placed on analysis of postimplementation long-term effects and determinants of sustainability.

\section{Further research}

There is a need for enhanced reporting of ASP implementation aligned with the CDC framework in GCC states. Further consideration should also be given to application of implementation theory to provide focus on facilitators and barriers to implementation. To facilitate identification and understanding of constructs that govern translation of research findings into real practice within the healthcare sector in GCC states, there is a need for rigorous qualitative in-depth research that utilizes implementation frameworks.

In conclusion, there appears to be a need to enhance the reporting of ASP implementation in GCC hospitals. Notably, ASP infrastructure is found to be insufficient and heterogenous. A rigorous infrastructure framework (leadership support, accountability and pharmacist expertise) is required to enhance efficacy and governance, and ensure the sustainability of implementation interventions (actions, tracking, reporting and education). Attention should be paid to the CDC framework during the development, implementation and reporting of ASP interventions. Action is required to identify facilitators and overcome barriers, where possible.

Conflict of interest statement None declared.

\section{Funding sources}

None.

\section{Appendix A. Supplementary data}

Supplementary data to this article can be found online at https://doi.org/10.1016/j.jhin.2020.09.004.

\section{References}

[1] World Health Organization. Antimicrobial stewardship programmes in health-care facilities in low- and middle-income countries. A WHO practical toolkit. Geneva: WHO; 2019. Available at: https://apps.who.int/iris/handle/10665/329404 [last accessed June 2020].

[2] Van Dijck C, Vlieghe E, Cox JA. Antibiotic stewardship interventions in hospitals in low-and middle-income countries: a systematic review. Bull World Health Organ 2018;96:266-80.

[3] Pulcini C, Binda F, Lamkang AS, Trett A, Charani E, Goff DA, et al. Developing core elements and checklist items for global hospital antimicrobial stewardship programmes: a consensus approach. Clin Microbiol Infect 2019;25:20-5.

[4] Ribero Pombo MH, Gandra S, Thompson D, Lamkang A, Pulcini C, Laxminarayan R. Global core standards for hospital antimicrobial stewardship programs: international perspectives and future directions. Doha: World Innovation Summit for Health; 2018. Available at: https://www.wish.org.qa/wp-content/uploads/ 
2018/11/IMPJ6078-WISH-2018-LHSN-AMR-181026-1.pdf [last accessed June 2020].

[5] Public Health England. Antimicrobial stewardship: start smart then focus. London: PHE; Available at: https://www.gov.uk/ government/publications/antimicrobial-stewardship-start-smartthen-focus [last accessed October 2019].

[6] European Centre for Disease Prevention and Control. European Union guidelines for the prudent use of antimicrobials in human health. Brussels: European Commission; 2017. Available at: https://ec.europa.eu/health/amr/sites/amr/files/amr_ guidelines_prudent_use_en.pdf [last accessed June 2020].

[7] Centers for Disease Control and Prevention. Core elements of hospital antibiotic stewardship programs. Atlanta, GA: CDC; 2014. Available at: http://www.cdc.gov/getsmart/healthcare/ implementation/core-elements.html [last accessed June 2020].

[8] Centers for Disease Control and Prevention. Core elements of hospital antibiotic stewardship programs. Atlanta, GA: CDC; 2019. Available at: https://www.cdc.gov/antibiotic-use/coreelements/hospital.html [last accessed June 2020].

[9] Division of Healthcare Quality Promotion. Hospital antibiotic stewardship. A.R. Patient Safety Portal. Available at: https:// arpsp.cdc.gov/profile/stewardship [last accessed January 2020].

[10] Pollack LA, van Santen KL, Weiner LM, Dudeck MA, Edwards JR, Srinivasan A. Antibiotic stewardship programs in U.S. acute care hospitals: findings from the 2014 National Healthcare Safety Network Annual Hospital Survey. Clin Infect Dis 2016;63:443-9.

[11] Lockwood AR, Bolton NS, Winton MD, Carter JT. Formalization of an antimicrobial stewardship program in a small community hospital. Am J Health Syst Pharm 2017;74:S52-60.

[12] Lane MA, Hays AJ, Newland H, Zack JE, Guth RM, Newland JG. Development of an antimicrobial stewardship program in an integrated healthcare system. Am J Health Syst Pharm 2019;76:34-43.

[13] Logan AY, Williamson JE, Reinke EK, Jarrett SW, Boger MS, Davidson LE. Establishing an antimicrobial stewardship collaborative across a large, diverse health care system. Jt Comm J Qual Patient Saf 2019;45:591-9.

[14] Al Kaabi MR, Tariq WUZ, Hassanein AA. Rising bacterial resistance to common antibiotics in Al Ain, United Arab Emirates. East Mediterr Health J 2011;17:479-84.

[15] Aly M, Balkhy HH. The prevalence of antimicrobial resistance in clinical isolates from Gulf Corporation Council countries. Antimicrob Resist Infect Control 2012;1:26.

[16] Jamsheer A, Rafay AM, Daoud Z, Morrissey I, Torumkuney D. Results from the Survey of Antibiotic Resistance (SOAR) 2011-13 in the Gulf states. J Antimicrob Chemother 2016;71:45-61.

[17] Balkhy HH, Assiri AM, Mousa $\mathrm{H}$ Al, Al-Abri SS, Al-Katheeri H, Alansari $\mathrm{H}$, et al. The strategic plan for combating antimicrobial resistance in Gulf Cooperation Council states. J Infect Public Health 2016;9:375-85.

[18] Public Health England. Antimicrobial stewardship: start smart then focus. London: PHE; 2015. Available at: https://www.gov. uk/government/publications/antimicrobial-stewardship-startsmart-then-focus [last accessed October 2019].

[19] World Health Organization. Global action plan on AMR. Geneva: WHO; 2016. Available at: https://www.who.int/antimicrobialresistance/global-action-plan/en/ [last accessed August 2020].

[20] Filice G, Drekonja D, Wilt T, Greer N, Butler M, Wagner B, et al. Antimicrobial stewardship programs in inpatient settings: a systematic review. Dep Veterans Aff Heal Serv Res Dev Serv 2013:1-150. PMID: 25411666.

[21] Wagner B, Filice GA, Drekonja D, Greer N, MacDonald R, Rutks I, et al. Antimicrobial stewardship programs in inpatient hospital settings: a systematic review. Infect Control Hosp Epidemiol 2014;35:1209-28.

[22] King S, Exley J, Taylor J, Kruithof K, Larkin J, Pardal M. Antimicrobial stewardship: the effectiveness of educational interventions to change risk-related behaviours in the general population: a systematic review. Rand Health Q 2016;5:2.

[23] Schuts EC, Hulscher MEJL, Mouton JW, Verduin CM, Stuart JWTC, Overdiek HWPM, et al. Current evidence on hospital antimicrobial stewardship objectives: a systematic review and meta-analysis. Lancet Infect Dis 2016;16:847-56.

[24] Nasr Z, Paravattil B, Wilby KJ. The impact of antimicrobial stewardship strategies on antibiotic appropriateness and prescribing behaviours in selected countries in the Middle East: a systematic review. East Mediterr Health J 2017;23:430-40.

[25] Alghamdi S, Shebl NA, Aslanpour Z, Shibl A, Berrou I. Hospital adoption of antimicrobial stewardship programmes in Gulf Cooperation Council countries: a review of existing evidence. J Glob Antimicrob Resist 2018;15:196-209.

[26] Cox JA, Vlieghe E, Mendelson M, Wertheim H, Ndegwa L, Villegas MV, et al. Antibiotic stewardship in low- and middleincome countries: the same but different? Clin Microbiol Infect 2017;23:812-8.

[27] Moher D, Shamseer L, Clarke M, Ghersi D, Liberati A, Petticrew M, et al. Preferred Reporting Items for Systematic Reviews and Meta-Analyses Protocols (PRISMA-P) 2015 statement. Rev Esp Nutr Hum Diet 2016;20:148-60.

[28] Hashad N, Tonna A, Dhayaneethie P, Stewart D. Antimicrobial stewardship program implementation in Gulf Cooperation Council states: a systematic review protocol. PROSPERO 2017:CRD42017079597. Available at: https://www.crd.york.ac. uk/prospero/display_record.php?ID=CRD42017079597.

[29] National Heart, Lung, and Blood Institute. Study quality assessment tools. Bethesda, MD: NHLBI; n.d. Available at: https:// www.nhlbi.nih.gov/health-topics/study-quality-assessment-tools [last accessed June 2020].

[30] The EQUATOR Network. Consolidated criteria for reporting qualitative research (COREQ): a 32-item checklist for interviews and focus groups. Oxford: The EQUATOR Network; n.d. Available at: https://www.equator-network.org/reporting-guidelines/ coreq/ [last accessed June 2020].

[31] National Heart, Lung, and Blood Institute. Background: development and use of study quality assessment tools. Bethesda, MD: NHLBI; n.d. Available at: https://www.nhlbi.nih.gov/node/80102 [last accessed June 2020].

[32] Bowling A. Research methods in health investigating health and health services. 3rd ed. New York: McGraw-Hill Education; 2009.

[33] Alghamdi S, Atef-Shebl N, Aslanpour Z, Berrou I. Barriers to implementing antimicrobial stewardship programmes in three Saudi hospitals: evidence from a qualitative study. J Glob Antimicrob Resist 2019;18:284-90.

[34] Al-Somai N, Al-Muhur M, Quteimat O, Hamzah N. The impact of clinical pharmacist and ID intervention in rationalization of antimicrobial use. Saudi Pharm J 2014;22:516-21.

[35] Baraka MA, Alsultan H, Alsalman T, Alaithan H, Islam MA, Alasseri AA. Health care providers' perceptions regarding antimicrobial stewardship programs (AMS) implementation - facilitators and challenges: a cross-sectional study in the Eastern province of Saudi Arabia. Ann Clin Microbiol Antimicrob 2019;18:26.

[36] El-Lababidi RM, Mooty M, Bonilla MF, Nusair A, Alatoom A, Mohamed S. Implementation and outcomes of an advanced antimicrobial stewardship program at a quaternary care hospital in the United Arab Emirates. J Am Coll Clin Pharm 2019;2:515-23.

[37] Dib JG, Al-Tawfiq JA, Al Abdulmohsin S, Mohammed K, Jenden PD. Improvement in vancomycin utilization in adults in a Saudi Arabian medical center using the Hospital Infection Control Practices Advisory Committee guidelines and simple educational activity. J Infect Public Health 2009;2:141-6.

[38] Al-Tawfiq JA. The pattern and impact of infectious diseases consultation on antimicrobial prescription. J Glob Infect Dis 2013;5:45-8.

[39] Amer MR, Akhras NS, Mahmood WA, Al-Jazairi AS. Antimicrobial stewardship program implementation in a medical intensive care 
unit at a tertiary care hospital in Saudi Arabia. Ann Saudi Med 2013;33:547-54.

[40] Tobaiqy M, Humaid S Al, Stewart D, Alotaibi FO, Qureshi KA, MacLure K, et al. Assessment of tigecycline prescription and patients' outcomes at three different hospitals in Saudi Arabia. Trop J Pharm Res 2015;14:1919-26.

[41] Al-Tawfiq JA, Momattin H, Al-Habboubi F, Dancer SJ. Restrictive reporting of selected antimicrobial susceptibilities influences clinical prescribing. J Infect Public Health 2015;8:234-41.

[42] Abdallah M, Badawi M, Amirah MF, Rasheed A, Mady AF, Alodat M, et al. Impact of carbapenem restriction on the antimicrobial susceptibility pattern of Pseudomonas aeruginosa isolates in the ICU. J Antimicrob Chemother 2017;72:3187-90.

[43] Alawi MM, Darwesh BM. A stepwise introduction of a successful antimicrobial stewardship program: experience from a tertiary care university hospital in western Saudi Arabia. Saudi Med J 2016;37:1341-9.

[44] Garcell HG, Arias AV, Sandoval CP, Valle Gamboa ME, Sado AB, Alfonso Serrano RN. Impact of a focused antimicrobial stewardship program in adherence to antibiotic prophylaxis and antimicrobial consumption in appendectomies. J Infect Public Health 2017;10:415-20.

[45] Momattin H, Al-Ali AY, Mohammed K, Al-Tawfiq JA. Benchmarking of antibiotic usage: an adjustment to reflect antibiotic stewardship program outcome in a hospital in Saudi Arabia. J Infect Public Health 2018;11:310-3.

[46] Aly NY, Omar AA, Badawy DA, Al-Mousa HH, Sadek AA. Audit of physicians' adherence to the antibiotic policy guidelines in Kuwait. Med Princ Pract 2012;21:310-7.

[47] El Hassan M, Elnour AA, Farah FH, Shehab A, Al Kalbani NM, Asim S, et al. Clinical pharmacists' review of surgical antimicrobial prophylaxis in a tertiary hospital in Abu Dhabi. Int J Clin Pharm 2014;37:18-22.

[48] Garcell HG, Arias AV, Fernandez EA, Guerrero YB, Serrano RNA. Antibiotic consumption during a 4-year period in a community hospital with an antimicrobial stewardship program. Oman Med J 2016;31:352-6.

[49] H Guanche G, Ariadna Villanueva A, Ra Nonato A. Quality of perioperative antibiotic prophylaxis in a community hospital in western Qatar. J Infect Dis Epidemiol 2017;3:045.

[50] Moher D, Liberati A, Tetzlaff J, Altman DG. Preferred Reporting Items for Systematic Reviews and Meta-Analyses: the PRISMA statement. PLoS Med 2009;6:e1000097.

[51] Peters DH, Tran NT, Adam T. Implementation research in health. Geneva: World Health Organization; 2013.

[52] Moullin JC, Sabater-Hernández D, Fernandez-Llimos F, Benrimoj SI. A systematic review of implementation frameworks of innovations in healthcare and resulting generic implementation framework. Health Res Policy Syst 2015;13:16.

[53] Alonge O, Rodriguez DC, Brandes N, Geng E, Reveiz L, Peters DH. How is implementation research applied to advance health in low-income and middle-income countries. BMJ Glob Health 2019;4:e-001257.

[54] Wilson PM, Sales A, Wensing M, Aarons GA, Flottorp S, Glidewell L, et al. Enhancing the reporting of implementation research. Implement Sci 2017;12:13.

[55] Qureshi AZ, Ullah S, Ullah R. The trend of hospital accreditation in the Kingdom of Saudi Arabia. Saudi Med J 2012;33:1350-1.

[56] Koornneef E, Robben P, Blair I. Progress and outcomes of health systems reform in the United Arab Emirates: a systematic review. BMC Health Serv Res 2017;17:672.

[57] Joint Commission. New antimicrobial stewardship standard. Jt Commiss Perspect 2016;36:1-3, 4, 8. Available at: https://www. jointcommission.org/-/media/enterprise/tjc/importedresource-assets/documents/new_antimicrobial_stewardship_ standardpdf.pdf? $\mathrm{db}=$ web\&hash $=69307456$ CCE435B134854392C7FA7D76 [last accessed June 2020].
[58] Malmgren A, Biswanger K, Lundqvist A, Zaoutis T. Education, decision support, feedback and a minor reward: a novel antimicrobial stewardship intervention in a Swedish paediatric emergency setting. Infect Dis 2019;51:559-69.

[59] Bolla C, Di Pietrantonj C, Ferrando E, Pernecco A, Salerno A, D'Orsi $M$, et al. Example of antimicrobial stewardship program in a community hospital in Italy. Med Mal Infect 2020;50:342-5.

[60] Nagel JL, Stevenson JG, Eiland EH, Kaye KS. Demonstrating the value of antimicrobial stewardship programs to hospital administrators. Clin Infect Dis 2014;59:S146-53.

[61] Antimicrobial Resistance National Committee. Kingdom of Saudi Arabia national action plan on combating antimicrobial resistance. Kingdom of Saudi Arabia: Antimicrobial Resistance National Committee; 2017. Available at: http://extwprlegs1.fao.org/ docs/pdf/sau171813.pdf [last accessed June 2020].

[62] Ministry of Health. Antimicrobial resistance national action plan. Oman: Ministry of Health; 2017. Available at: http:// extwprlegs1.fao.org/docs/pdf/oma171516.pdf [last accessed June 2020].

[63] Walia K, Ohri VC, Mathai D. Antimicrobial stewardship programme (AMSP) practices in India. Indian J Med Res 2015;142:130-8.

[64] Campbell J, Dussault G, Buchan J, Pozo-Martin F, Guerra Arias M, Leone C, et al. A universal truth: no health without a workforce. Forum report, third global forum on human resources for health, Recife, Brazil. Geneva: WHO; 2013. Available at: https://www. who.int/workforcealliance/knowledge/resources/GHWA-a universal_truth_report.pdf?ua=1 [last accessed June 2020].

[65] Ten Oever J, Harmsen M, Schouten J, Ouwens M, van der Linden PD, Verduin CM, et al. Human resources required for antimicrobial stewardship teams: a Dutch consensus report. Clin Microbiol Infect 2018;24:1273-9.

[66] Maeda M, Muraki Y, Kosaka T, Yamada T, Aoki Y, Kaku M, et al. Essential human resources for antimicrobial stewardship teams in Japan: estimates from a nationwide survey conducted by the Japanese Society of Chemotherapy. J Infect Chemother 2019;25:653-6.

[67] Castro-Sánchez E, Gilchrist M, Ahmad R, Courtenay M, Bosanquet J, Holmes AH. Nurse roles in antimicrobial stewardship: lessons from public sectors models of acute care service delivery in the United Kingdom. Antimicrob Resist Infect Control 2019;8:162.

[68] Garau J, Bassetti M. Role of pharmacists in antimicrobial stewardship programmes. Int J Clin Pharm 2018;40:948-52.

[69] Simões AS, Maia MR, Gregório J, Couto I, Asfeldt AM, Simonsen GS, et al. Participatory implementation of an antibiotic stewardship programme supported by an innovative surveillance and clinical decision-support system. J Hosp Infect 2018;100:257-64.

[70] Bond SE, Chubaty AJ, Adhikari S, Miyakis S, Boutlis CS, Yeo WW, et al. Outcomes of multisite antimicrobial stewardship programme implementation with a shared clinical decision support system. J Antimicrob Chemother 2017;72:2110-8.

[71] Kuper KM, Nagel JL, Kile JW, May LS, Lee FM. The role of electronic health record and add-on clinical decision support systems to enhance antimicrobial stewardship programs. Infect Control Hosp Epidemiol 2019;40:501-11.

[72] Foral PA, Anthone JM, Destache CJ, Vivekanandan R, Preheim LC, Gorby GL, et al. Education and communication in an interprofessional antimicrobial stewardship program. J Am Osteopath Assoc 2016;116:588-93.

[73] Centers for Disease Control and Prevention. Framework for program evaluation in public health. MMWR Recomm Rep 1999;48:1-40.

[74] Fleiszer AR, Semenic SE, Ritchie JA, Richer MC, Denis JL. The sustainability of healthcare innovations: a concept analysis. J Adv Nurs 2015;71:1484-98. 